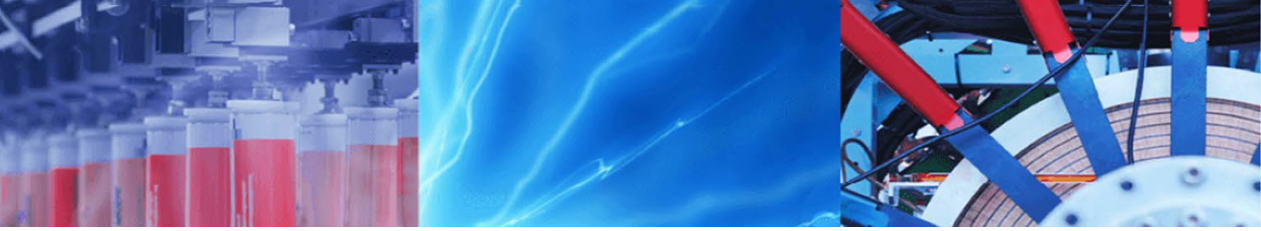

Research Article

\title{
Effects of Sn-foil addition on the microstructure and mechanical properties of laser welding joint for dual phase steel and magnesium alloy
}

\author{
Dianwu Zhou ${ }^{1} \cdot$ Jinshui Liu ${ }^{1} \cdot$ Zhe Tan $^{1} \cdot$ Shaohua Xu ${ }^{1}$
}

(c) Springer Nature Switzerland AG 2019

\begin{abstract}
The aim of present research was investigating the effects of $\mathrm{Sn}$-foil addition on the microstructure and mechanical properties of laser welding joint for DP600 dual phase steel and AZ31 magnesium alloy in an overlap steel-on-magnesium configuration. Results showed that when Sn-foil was added as interlayer, some defects, such as surface pit, spatter and softening in heat affected zone, can be avoided,oxide and porosity are also no obvious in the weld. A good weld surface with continuous and uniform fish scale welding line is obtained. Fe-Sn phases, such as $\mathrm{FeSn}, \mathrm{Fe}_{1.3} \mathrm{Sn}$, and Fe $\mathrm{Sn}_{3}$, are formed in steel side, while $\mathrm{Mg}_{2} \mathrm{Sn}$ is found in magnesium side. These new phases are favorable for realizing the steel/ magnesium metallurgical connection, and adding Sn-foil laser welding is an effective way in joining steel to magnesium alloy. However, mechanical property for steel/magnesium joint is closely connected with the brittleness of $\mathrm{Mg}_{2} \mathrm{Sn}$ phase, how to regulate its brittleness is the key in order to improve the joint properties.
\end{abstract}

Keywords Laser welding $\cdot$ Sn-foil $\cdot$ Steel/magnesium $\cdot$ Microstructure $\cdot$ Property

\section{Introduction}

Up to now, magnesium and its alloys are one of the lightest metal structural materials with some advantages, such as high specific strength, specific stiffness, good dimensional stability, easy recycling, which is thought as the first choice material for energy conservation and emissions reduction [1-3]. It is unavoidable for steel connection with magnesium when magnesium and its alloys are used in automotive industry. However, it is difficult for joining steel to magnesium alloy due to the difference in melting and boiling point, no solid solutions or no generating intermetallic compounds (IMCs), in addition, oxide with high melting point are easily generated at steel/magnesium interface [4]. Liu [5], Liu et al. [6], Liu and Qi [7] and Zhao et al. [8] explored an overlap magnesium-on-steel configuration based on solid-state pulsed laser and electric arc complex heat sources, but the connection between steel and magnesium alloy can be not effectively realized due to low energy utilization and limited agitation effect [9]. In our previous work, finite element model of steel/magnesium laser welding was set up, a good agreement about the shape and size of molten pool from the experimental results combined with numerical simulations was found [10]. With the improvement of laser beam quality and its output power [11, 12], it is possible for joining steel to magnesium alloy by the use of laser welding technology.

In this work, laser welding for steel and magnesium alloy in an overlap steel-on-magnesium configuration was put forward, the effects of Sn-foil addition on the microstructure and mechanical properties of laser welding joint for DP600 dual phase steel and AZ31 magnesium alloy was presented, welding mechanism of joint was also clarified. When Sn-foil was added as interlayer, some defects, such as surface pit, spatter and softening in heat affected zone (HAZ), can be avoided, oxide and porosity are also no

Dianwu Zhou, ZDWe_mail@126.com |'State Key Laboratory of Advanced Design and Manufacturing for Vehicle Body, Hunan University, Changsha 410082, China.

SN Applied Sciences (2019) 1:694 | https://doi.org/10.1007/s42452-019-0729-4

Received: 12 November 2018 / Accepted: 4 June 2019 / Published online: 10 June 2019

SN Applied Sciences

A SPRINGER NATURE journal 
obvious. A good weld surface is obtained. Metallurgical connection can be realized for steel to magnesium alloy by adding $\mathrm{Sn}$-foil. Through the above studies, the experimental basis will be provided for steel/magnesium structure parts application in modern transportation.

\section{Experimental materials and methods}

DP600 dual phase steel, with composition of Fe-0.079C$0.10 \mathrm{Si}-1.25 \mathrm{Mn}-0.0049 \mathrm{~S}-0.015 \mathrm{P}-0.023 \mathrm{Al}$ (wt\%), and AZ31 magnesium alloy, with composition of Mg-3.12Al-0.95Zn$0.15 \mathrm{Mn}-0.10 \mathrm{Si}(\mathrm{wt} \%)$, were selected as experimental materials in this work. Their sizes were $100 \times 30 \times 1.4 \mathrm{~mm}$ and $100 \times 30 \times 1.8 \mathrm{~mm}$, respectively. Steel sheet was placed on magnesium sheet in an overlap configuration. Sn-foil, with $99.0 \%$ purity, $40 \times 30 \times 0.18 \mathrm{~mm}$ size, was added between two sheets as interlayer, as shown in Fig. 1. Prior to welding, the surfaces of steel and magnesium sheet were both polished by using sandpaper in order to remove oxide film, oil pollutant and metal debris were also removed by means of acetone, Sn-foil was polished to flat and bright with fine sandpaper. A special welding fixture was used to clamp welding material to reduce the clearance between two sheets.

The experiment was carried out using a 4-kW fiber laser (YLS-4000-CL) with beam wavelength of $1070 \mathrm{~nm}$. The beam was focused to obtain a spot size of $0.4 \mathrm{~mm}$ by the use of focusing mirror with a $200 \mathrm{~mm}$ focal length. The laser mode was TEM 00 and the angle alpha of beam divergence was less than $0.15 \mathrm{rad}$. Argon, with $99.9 \%$ pure

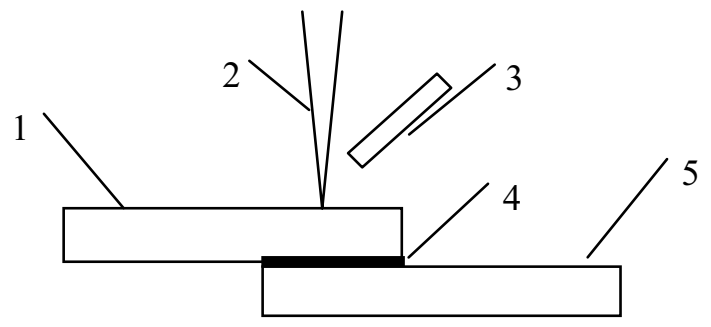

Fig. 1 Principle map of adding Sn-foil steel/magnesium laser lap welding. 1-dual phase steel 2-laser beam 3-blowing side protective gas 4-Sn-foil 5-magnesium and at a flow rate of $15 \mathrm{~L} / \mathrm{min}$, was serve as the shielding gas to protect molten metal and back surface from oxidation during the welding process. Welding parameters were constantly adjusted to acquire a good weld surface. After welding, standard test sample was machined by wire cutting. Steel side was corroded with $5 \%$ nitric acid alcohol solution, while magnesium side was corroded by picric acid solution. The measurements of the hardness in the cross sections of weld was finished by HV- 50 hardness tester under the condition that load is $200 \mathrm{~g}$ and hold time is $45 \mathrm{~s}$. The shear tensile tests were operated by Css225 testing machine with a speed of $1 \mathrm{~mm} / \mathrm{min}$. Fracture morphologies of the samples were observed through the use of scanning electron microscopy (SEM). Grain size, microstructure and interface elements distribution of weld were performed by FEI Quanta 200 scanning electron microscopy equipped with spectrometer (EDS) and electron back-scattered diffraction (EBSD) probe. EBSD sample was prepared by mechanical grinding combined with electrolytic polishing. Electrolytic polishing parameters were selected, and current was 2-3 A, temperature was $25^{\circ}-30^{\circ}$, electrolyte was $10 \% \mathrm{HCLO}_{4}+90 \% \mathrm{C}_{2} \mathrm{H}_{2} \mathrm{OH}$. The phase composition of the weld was identified by $\mathrm{X}$-ray diffraction (XRD).

\section{Results and discussions}

\subsection{Surface morphology and microstructure of joints}

Figure 2 shows surface morphology of joint. When Sn-foil was not added, it can be seen that magnesium alloy sheet burns seriously and sparks in all directions [10] (Fig. 2a). Due to the larger vapor pressure, magnesium vapor escapes from molten pool, which leads to spatter of steel molten pool, and holes formed in the depression of weld (Fig. 2b).

Laser welding with Sn-foil was carried out to obtain a good weld surface. In this work, defocusing amount was selected as $2 \mathrm{~mm}$ to avoid excessive heat input and prevent magnesium sheet vaporization. As far as laser reflectivity on steel surface was concerned, deflection direction of laser head was $10^{\circ}$. The process parameters, such as
Fig. 2 Surface morphology of joint without Sn-foil, a oxidation and splatter $\mathbf{b}$ weld unfilled
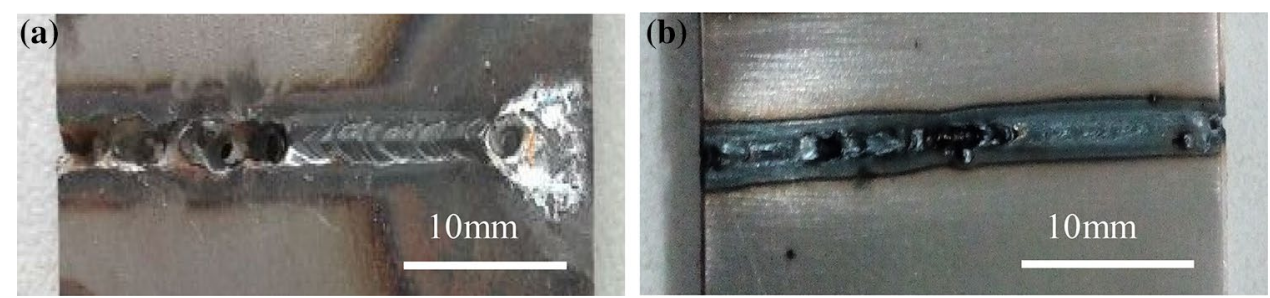
Fig. 3 Surface morphology of joint with Sn-foil under different laser powers a $1200 \mathrm{~W}, \mathbf{b}$ $1400 \mathrm{~W}, \mathrm{c} 1500 \mathrm{~W}, \mathbf{d} 1600 \mathrm{~W}$
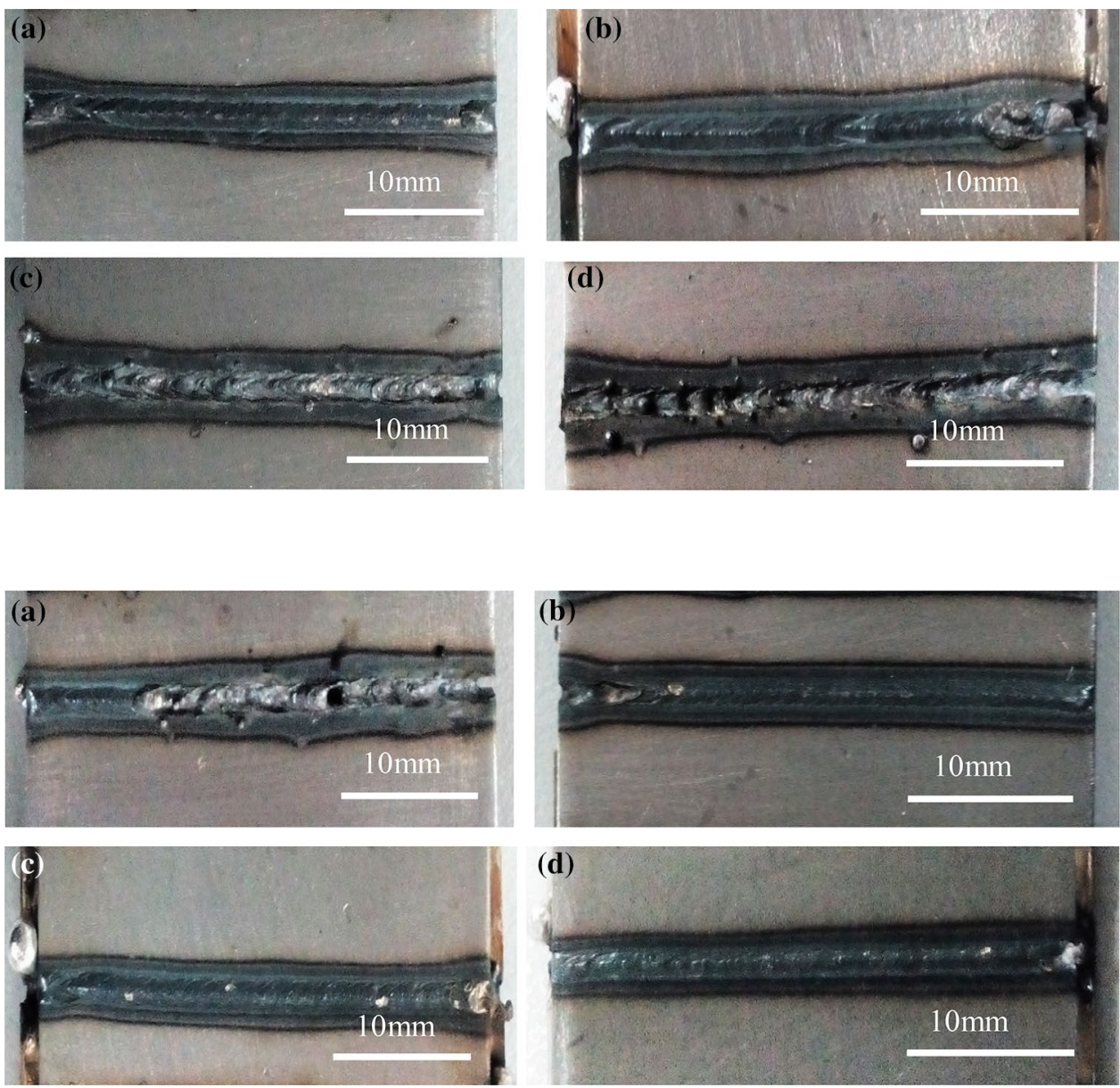

Fig. 4 Surface morphology of joint with Sn-foil under different welding speeds a $20 \mathrm{~mm} / \mathrm{s}$, b $25 \mathrm{~mm} / \mathrm{s}$, c $30 \mathrm{~mm} / \mathrm{s}$, d $35 \mathrm{~mm} / \mathrm{s}$ laser power, welding speed, etc., were adjusted according to the single factor method. From surface morphology of joint shown in Fig. 3, it was found that when laser power was below $1200 \mathrm{~W}$, local width of weld was narrow, which means the upper steel sheet less melted while magnesium alloy sheet more melted. With the increase of laser power, weld width was uniform and gradually widened. When laser power was $1400 \mathrm{~W}$, weld surface was continuous and uniform, no splash and sag, but laser power reaches $1600 \mathrm{~W}$, weld surface adheres to metal particles caused by splash. Generally under the condition of larger laser power, sheet temperature was above the boiling point of magnesium alloy, it was easy for metal vapor produced in the overflow process to take away molten pool. If splashing liquid metal cannot be replenished, weld surface was uneven due to the loss of metal. From the above, when laser power was less than $1400 \mathrm{~W}$, it can be obtained for steel/magnesium weld with the best surface morphology.

From surface morphology of joint shown in Fig. 4, it was found that when welding speed was $20 \mathrm{~mm} / \mathrm{s}$, weld surface appears a pit and spatter residual metal particles (Fig. 4a). When welding speed reaches $25 \mathrm{~mm} / \mathrm{s}$, no spatter was found, continuous and uniform weld can be obtained
Table 1 Optimized welding parameters of steel/magnesium laser welding with Sn-foil

\begin{tabular}{lllll}
\hline $\begin{array}{l}\text { Laser power } \\
(\mathrm{W})\end{array}$ & $\begin{array}{l}\text { Welding } \\
\text { speed } \\
(\mathrm{mm} / \mathrm{s})\end{array}$ & $\begin{array}{l}\text { Defocus } \\
(\mathrm{mm})\end{array}$ & $\begin{array}{l}\text { Gas flow } \\
\text { rate }(\mathrm{L} / \mathrm{min})\end{array}$ & $\begin{array}{l}\text { Deflection } \\
\text { angle }\left(^{\circ}\right)\end{array}$ \\
\hline 1400 & 30 & +2 & 15 & 10 \\
\hline
\end{tabular}

(Fig. 4b). When welding speed was $30 \mathrm{~mm} / \mathrm{s}$, welding surface was clear with fish scale welding lines (Fig. 4c). However, when welding speed reaches $35 \mathrm{~mm} / \mathrm{s}$, weld width was narrowed (Fig. 4d) due to small heat input.

Based on analysis of surface morphology of joints, a good weld surface can be obtained, and optimized welding process parameters were listed in Table 1.

Figure 5 shows microstructure of weld cross section with Sn-foil under optimized welding parameters. It was found that in weld center there is a banded structure which spreads from the bottom edge of molten pool to the top of weld (Fig. 5a). When local structure was amplified, as shown in Fig. 5b, it was found that the banded material with metallic luster is caused by the floating of liquid $\mathrm{Sn}$ metal, which can be confirmed by EDS analysis 
Fig. 5 Microstructure of DP600 and AZ31 a welding joint, $\mathbf{b}$ magnification of $\mathrm{a} 1$ and $\mathrm{a} 2$ region in (a)
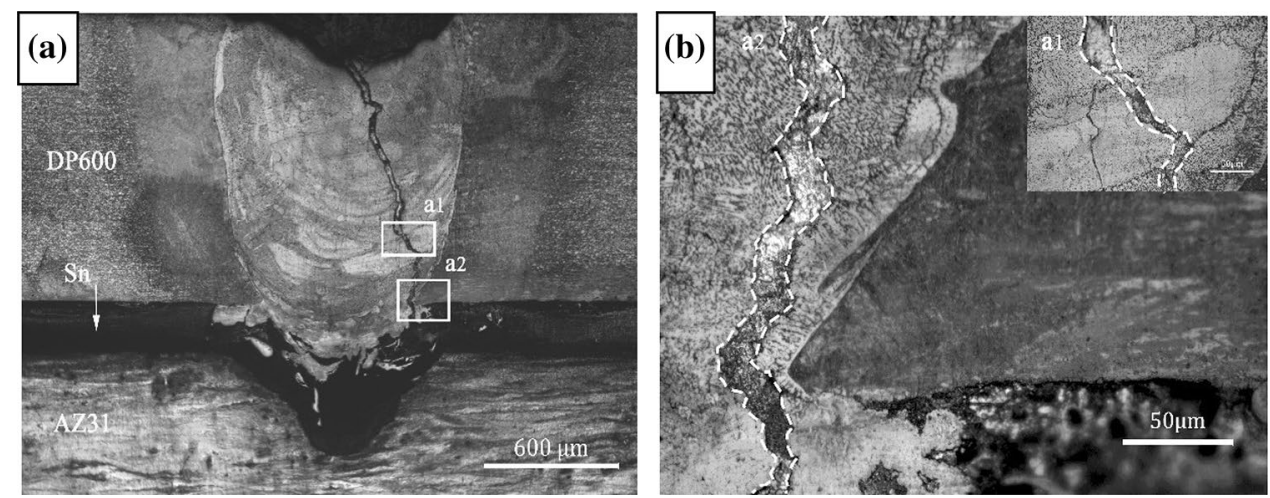

Table 2 Chemical compositions of joint by EDS analysis in Fig. 10 (at.pct)

\begin{tabular}{llllllllll}
\hline Element & $\mathrm{A}$ & $\mathrm{B}$ & $\mathrm{C}$ & $\mathrm{D}$ & $\mathrm{E}$ & $\mathrm{F}$ & $\mathrm{I}$ & II & III \\
\hline $\mathrm{Mg}$ & - & 79.10 & - & - & - & - & 90.53 & 72.00 & 67.36 \\
$\mathrm{Fe}$ & 93.81 & - & 96.27 & 63.40 & 81.24 & 02.17 & - & 01.53 & 01.33 \\
$\mathrm{Sn}$ & 03.99 & 20.90 & 03.73 & 36.60 & 16.14 & 50.93 & 09.47 & 26.47 & 31.31 \\
$\mathrm{Mn}$ & 02.20 & - & - & - & 01.54 & 0.81 & - & - & - \\
$\mathrm{Si}$ & - & - & - & - & 01.08 & - & - & - & - \\
$\mathrm{O}$ & & & & & - & 46.07 & - & - & - \\
\hline
\end{tabular}

in F zone in Table 2. In addition, no large amount of oxide and porosity were found in the transition zone of weld and steel/magnesium joint, which indicates that adding Sn-foil inhibits the interaction between $\mathrm{Mg}$ and $\mathrm{O}$ elements. However, there was no porosity, on the one hand, the porosity of the deformed magnesium alloy used in this work is smaller than that of die-casting magnesium alloy [13], the oxide film on the surface of magnesium and steel sheet are both cleaned thoroughly before welding, and molten pool is effectively protected by high purity Ar gas. On the other hand, $\mathrm{Mg}$ and zinc vapors with lower melting point are formed due to evaporation in the welding process, but these vapors can be escaped form the banded channel (Fig. 5b) or the gap between steel/magnesium sheets (Fig. 5a). Hence, weld porosity was effectively controlled.

Phase distribution and average grain size of parent metal, HAZ and steel/magnesium joints (note: corresponding to the position of b1, b2 and b3 in Fig. 6) were analyzed by using EBSD. According to EBSD orientation diagram (Fig. 7b, c) of HAZ and weld, it can be clearly seen that two regions with different grain sizes are separated by the black dotted line as dividing line. The phase analysis results were shown in Fig. 8. It was found that martensite, ferrite and residual austenite in DP600 parent metal (Fig. 8a) account for $41.8 \%, 57.6 \%, 0.6 \%$, respectively, and average grain size is $3.84 \mu \mathrm{m}$. Two regions with distinct grain size in HAZ were shown in Fig. 8b. It can be seen that average grain size is smaller than that of parent material. Grain size of HAZ may be caused by the deformation of re-crystallization under the effect of laser welding thermal

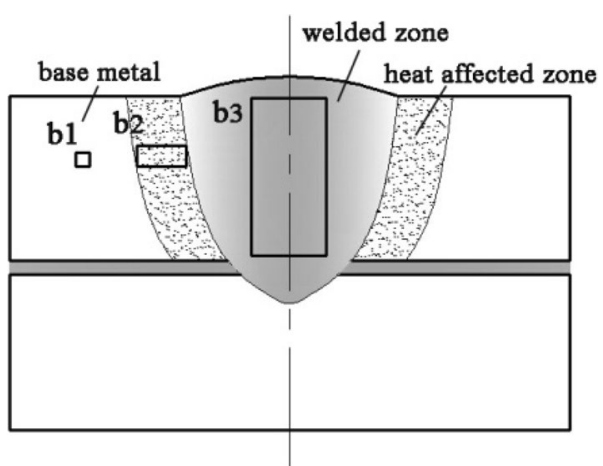

Fig. 6 Location of three EBSD test areas (b1, b2 and b3) in cross section of joint

cycle for rolled dual phase steel with a large number of internal storage distortion energy. However, grain continues to grow in HAZ due to the heat, which leads to two regions with different grain sizes. Average grain size of weld is larger than that of other zone, martensite, ferrite and residual austenite account for $40.1 \%, 57.5 \%, 2.40 \%$, respectively. Compared with parent material, corresponding content is basically the same. According to the above, when Sn-foil was added to steel/magnesium interfacial layer in an overlap steel-on-magnesium configuration, the upper dual phase steel welded joint is mainly ferrite and martensite, and softening in HAZ can be avoided.

Overall morphology and elements distribution in the transition zone of steel/magnesium joint were shown in Fig. 9. According to Fig. 9b, d, It was found that when 


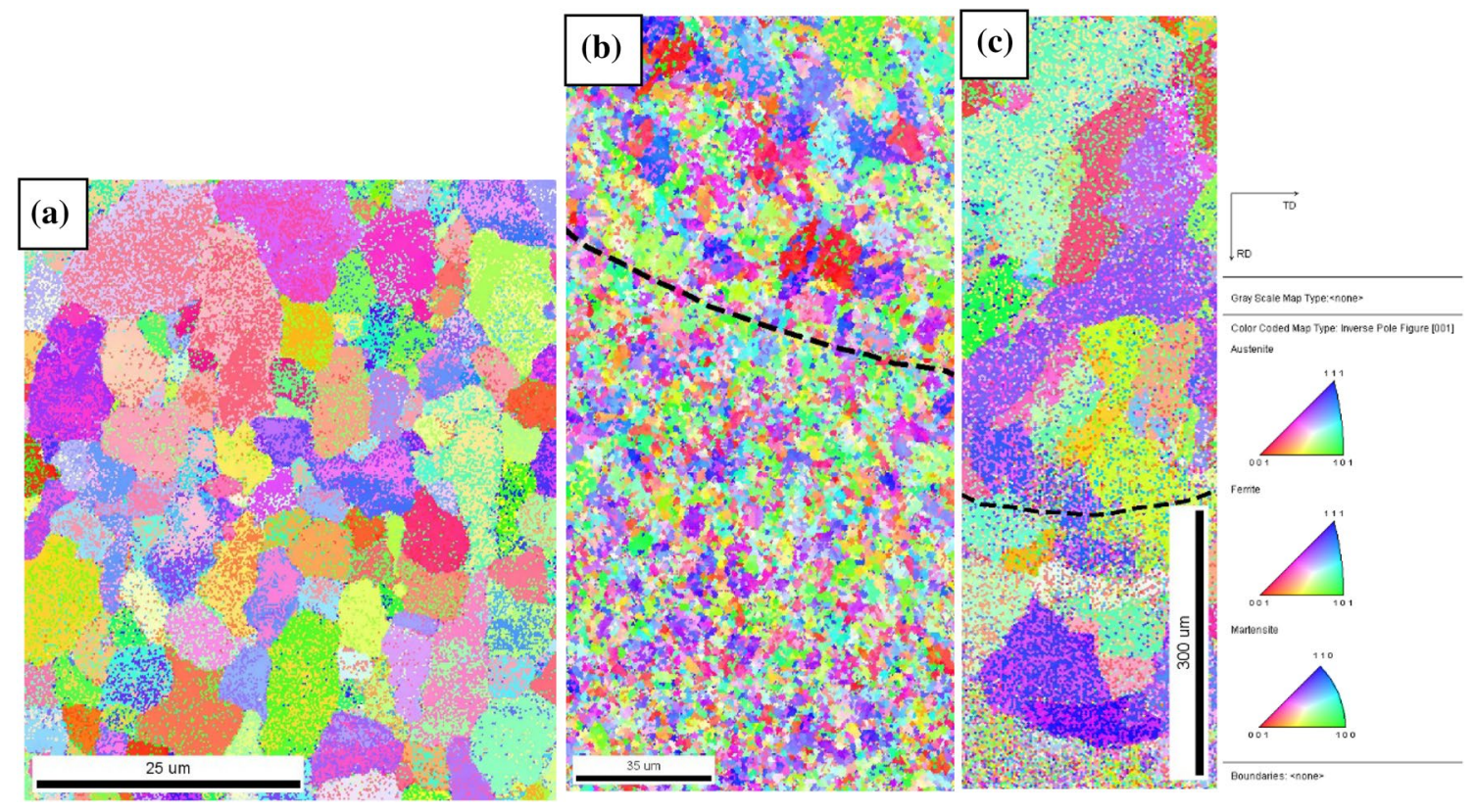

Fig. 7 EBSD maps of micro zone in steel/Sn/Mg joint $\mathbf{a} \mathbf{b}$ and $\mathbf{c}$ are from the region $\mathbf{b} 1, \mathrm{~b} 2$ and $\mathbf{b} 3$ in Fig. 6

Fig. 8 Different zones of joint a volume fraction of each phases, $\mathbf{b}$ average grain size
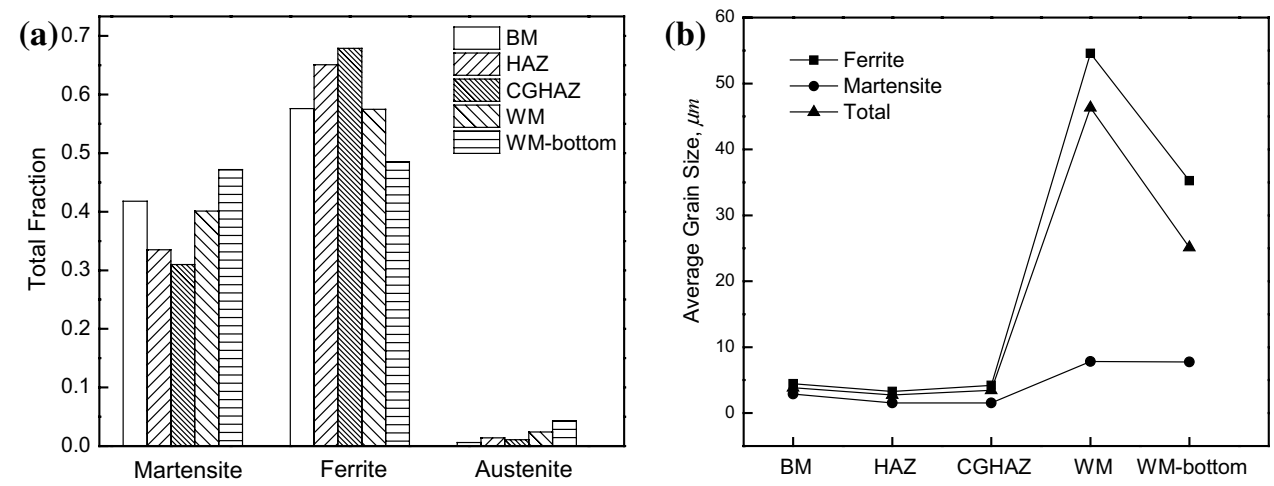

Sn-foil is added, Sn and iron fuse well, and no Mg element is found (Fig. 9c), which means that Mg does not interact with $\mathrm{Sn}$ in molten pool inner zone. Further analysis shows that in the melt pool end of magnesium side, the phenomenon of "Mg-floating and Sn-sinking" appears, transition zone with uniform distribution of two elements is formed, which indicates the interaction between $\mathrm{Mg}$ and $\mathrm{Sn}$ elements. In addition, uniformly distributed $\mathrm{Sn}$ element exists at the bottom of Fe-rich zone, which is caused by laser stirring, and metal at the bottom of molten pool flows in a circular from the bottom to the top [9]. Hence, it is beneficial to the interaction between Fe and Sn, and the fusion of Sn and molten pool. Here, no $\mathrm{Mg}$ is found near steel molten pool, considering that the melting point of steel is higher than that of $\mathrm{Mg}$, and the existence of $\mathrm{Sn}$-foil has a certain effect on the diffusion of $\mathrm{Mg}$, thus, no $\mathrm{Mg}$ was found in steel side weld pool. As can be seen from the above, when Sn-foil is added in laser welding steel/magnesium, the connection between $\mathrm{Sn}$ and steel, $\mathrm{Sn}$ and magnesium are both seen in molten pool and its end and side, respectively, thus it was realized for indirect connections between steel and magnesium.

Figure 10 shows SEM image of Sn-added joint. When I zone in Fig. 10a was magnified, it was found that this zone contains a large number of dendritic crystals. From the EDS results at A, B Zone in Fig. 10b and listed in Table 2, it was found that at $A$ zone it is mainly for $\mathrm{Fe}$. At $\mathrm{B}$ zone, the $\mathrm{Mg} / \mathrm{Sn}$ ratio is very close to $4: 1$. Thus $\mathrm{Mg}-\mathrm{Sn}$ phase may be formed at $\mathrm{B}$ zone according to the $\mathrm{Mg}-\mathrm{Sn}$ binary phase diagram. When 2 zone in Fig. 10a 
Fig. 9 Element distribution in magnesium transition zone of joint a SE image, $\mathbf{b}$ Fe mapping, c Mg mapping, d Sn mapping
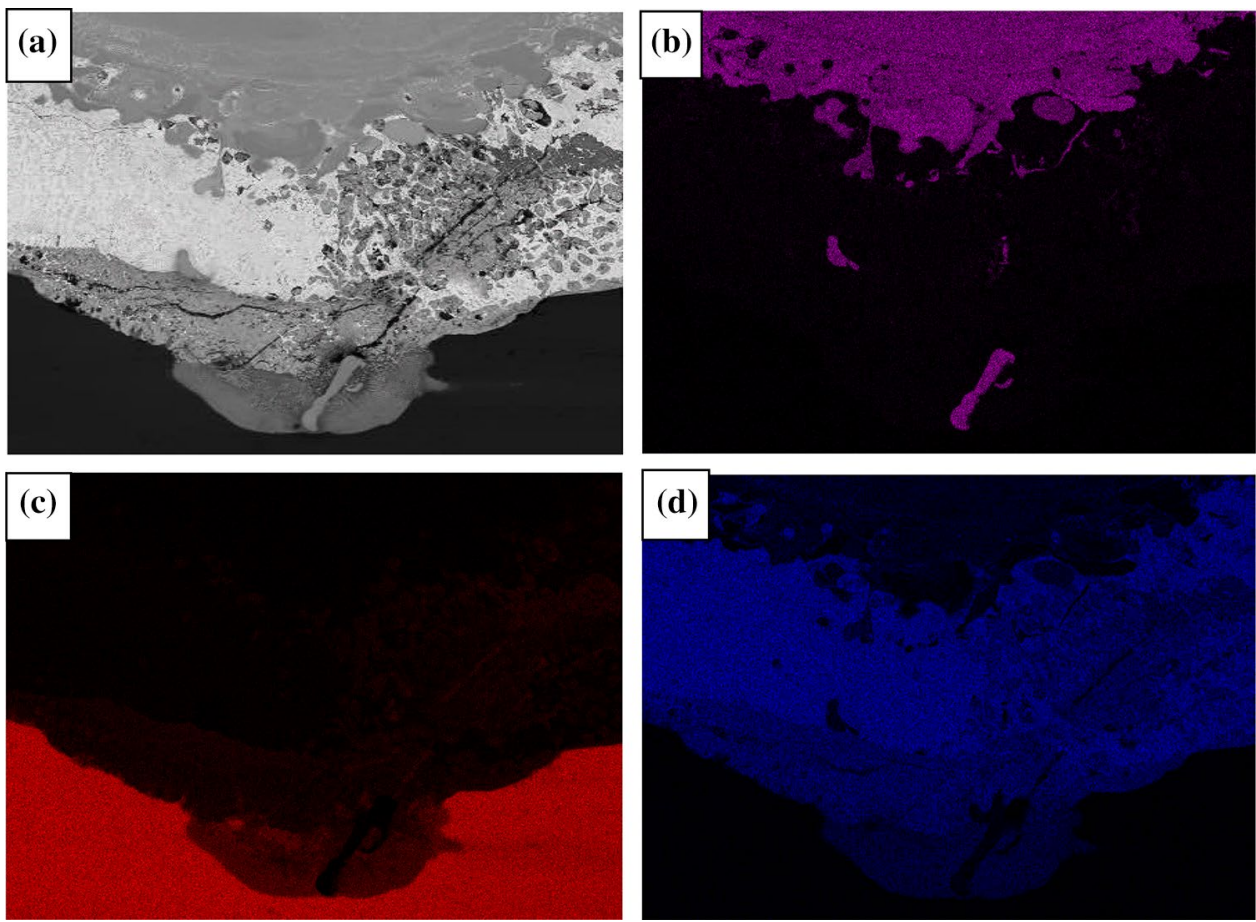

is magnified, it is found that there are many dendritic intermediates. They are divided into three regions. The thickness of I region is about 5-7 $\mu \mathrm{m}$, and a lot of small white particles are diffusely distributed in this region (Fig. 10e), its main content is Mg. At II region, there are a large number of columnar dendrites with the tendency for growing toward magnesium side. The $\mathrm{Mg} / \mathrm{Sn}$ ratio is close to 2:1, indicating that dendritic structure is $\mathrm{Mg}_{2} \mathrm{Sn}$. A similar analysis has been made at III region, the same results are found, $\mathrm{Mg}_{2} \mathrm{Sn}$ is also supposed to be formed. When 3 zone in Fig. 10a at the bottom of steel side molten pool is enlarged, as shown in Fig. 10d, it was found that the Sn contents is less, mainly for Fe. According to Fe-Sn binary phase diagram [14], solid solution will be formed at high temperature, and it may change into a-Fe and FeSn ICMs. Figure 10 f shows SEM image of a1 zone in Fig. 5. Based on the EDS results in Table 2, the Fe content at F zone is less, mainly for $\mathrm{Sn}$, while the element composition at $E$ zone is the same as dual phase steel, which means that banded material described above may be a "escape channel" for the lower magnesium vapor.

In our previous work [10], XRD analysis was conducted to determine phase structure type of weld, as shown in Fig. 11. It can be seen found that $\mathrm{FeSn}, \mathrm{Fe}_{1.3} \mathrm{Sn}$, $\mathrm{Fe}_{3} \mathrm{Sn}$ and $\mathrm{Mg}_{2} \mathrm{Sn}$ are formed at the weld interface, which is consistent with the EDS analysis results in this work. Grounded on above, Fe-Sn phases, such as FeSn,
$\mathrm{Fe}_{1.3} \mathrm{Sn}$, and $\mathrm{Fe}_{3} \mathrm{Sn}$, are formed in steel side, $\mathrm{Mg}_{2} \mathrm{Sn}$ is found in magnesium side. These new phases are favorable for realizing steel/magnesium metallurgical connection, and laser welding with $\mathrm{Sn}$-foil is an effective way in joining steel to magnesium alloy.

\subsection{Hardness and mechanical properties of weld}

Figure 12 shows weld hardness distribution with $\mathrm{Sn}$-foil. It was found that transverse hardness of steel parent material is about $191 \mathrm{HV}_{0.5}$, weld zone is $13.6 \%$ higher than that of HAZ, and 2.1 times of parent material, shown in Fig. 12a, which means that softening phenomenon does no appear in the upper dual phase steel. In terms of longitudinal hardness distribution, shown in Fig. 12b, weld hardness increases first and then decreases. The central hardness of steel side is slightly higher than that of the top, while the top is about $600 \mu \mathrm{m}$ where hardness reaches the maximum value (about $436 \mathrm{HV}_{0.5}$ ). Hardness of steel side is small in depth range of $0-800 \mathrm{~mm}$, and the average value is $398.3 \mathrm{HV}_{0.5}$. In the cooling process, there is little difference for the cooling rate between the upper and the middle, thus difference in microhardness is small. The bottom hardness of steel side gradually decreases, and hardness value is about 292.7 $\mathrm{HV}_{0.5}$. The hardness of magnesium side is lower than that of steel side, its lowest value is $58.86 \mathrm{HV}_{0.5}$, and hardness of this zone is lower than 75.35 $\mathrm{HV}_{0.5}$, with the average value of magnesium alloy, which 
Fig. 10 SEM image of microstructures of joint a cross-section, $\mathbf{b}, \mathbf{c}$ and $\mathbf{d}$ are amplified region 1 , region 2 and region 3 in (a), e amplification of region I in transition region in (c), $\mathbf{f}$ amplification of a1 region in (e)
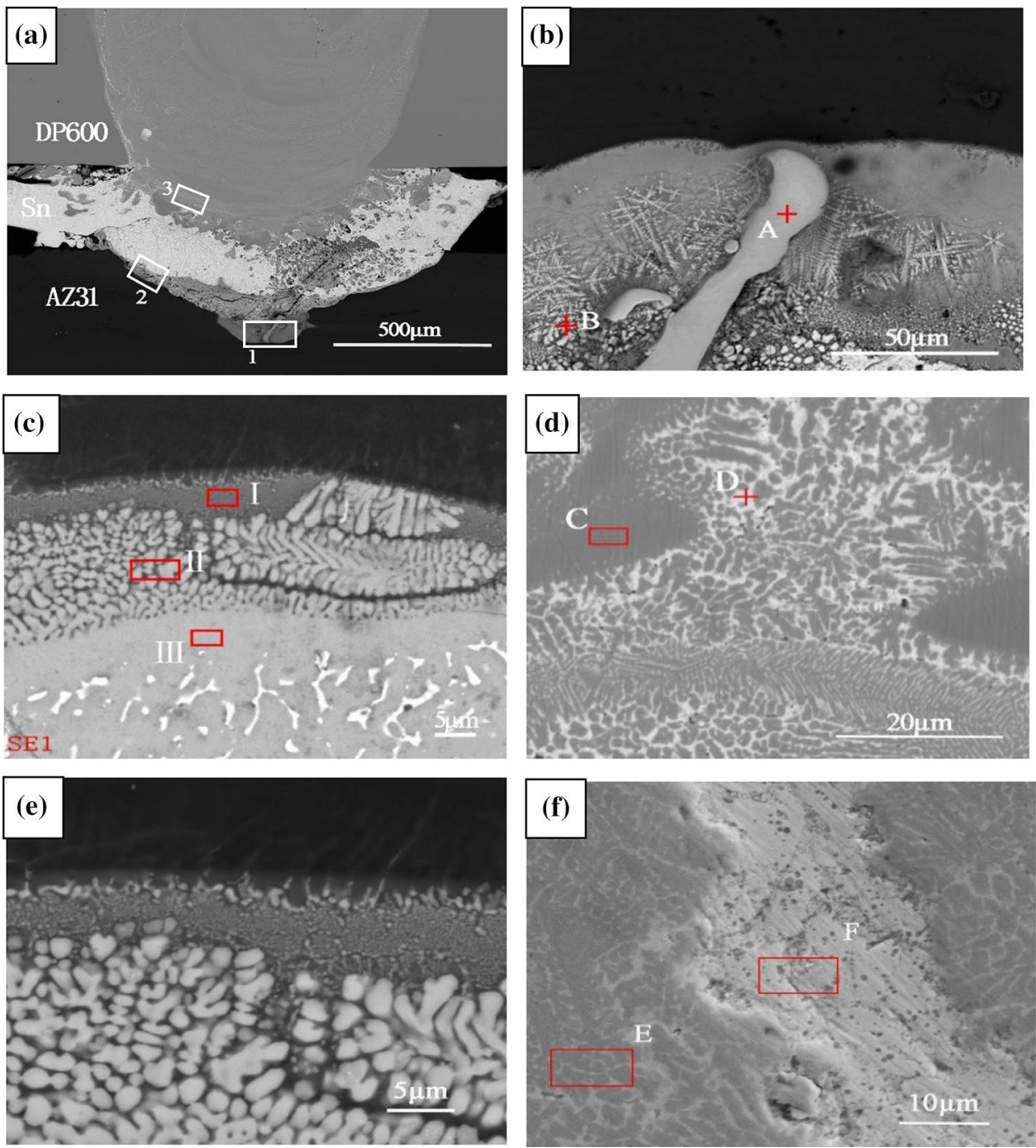

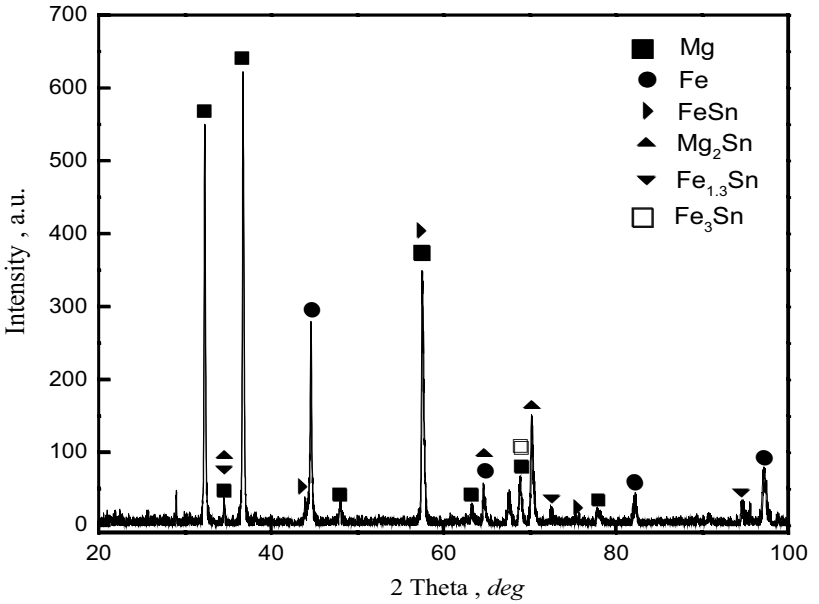

Fig. 11 XRD spectrum of DP600/AZ31 weld joint with Sn-foil indicates that interface zone is the weakest in the whole weld. In addition, some new phases, such as FeSn and $\mathrm{Fe}_{3} \mathrm{Sn}$, are formed in steel side, while $\mathrm{Mg}_{2} \mathrm{Sn}$ is formed in magnesium side. In previous research, $\mathrm{FeSn}$ and $\mathrm{Fe}_{3} \mathrm{Sn}$ are taken into account stable and ductile phase, while $\mathrm{Mg}_{2} \mathrm{Sn}$ is brittle phase [15]. Generally speaking, hardness of ductile phase is lower than that of brittle phase. Hence, the lower hardness of steel side is caused by FeSn and $\mathrm{Fe}_{3} \mathrm{Sn}$ in transition zone. On the basis of SEM analysis, there is continuous $\mathrm{Mg}_{2} \mathrm{Sn}$ phase with thickness of $20-40 \mu \mathrm{m}$ in the bottom of magnesium molten pool. It is inferred that lower hardness of the bottom of magnesium side is caused by the smaller thickness of $\mathrm{Mg}_{2} \mathrm{Sn}$ brittleness.

Figure 13 shows energy spectrum of weld with different detection position, and the EDS results were shown in Table 3. It can be seen that in the top of steel side, the Fe content at 1 and 2 zone is both higher, and corresponding hardness is also higher. The closer molten pool in steel side is to the Sn-foil position of the middle layer, the more $\mathrm{Sn}$ 
Fig. 12 Micro-hardness distribution in each region of joint a transverse hardness distribution, b longitudinal hardness distribution
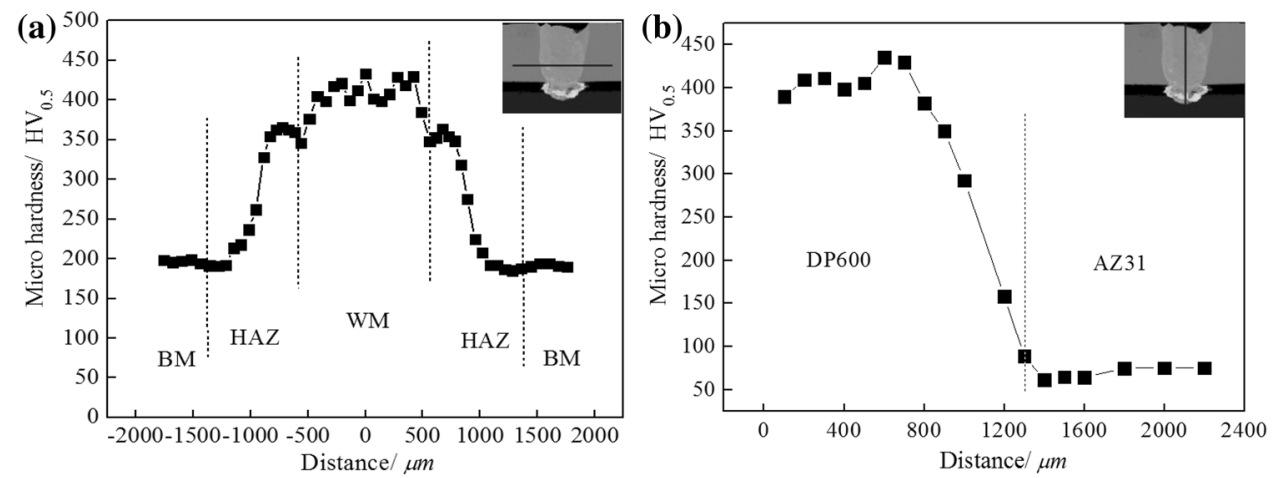

content and the hardness gradually decrease. At 3 zone, the $\mathrm{Sn}$ content is $25.05 \%$, and the hardness decreased to 158.4 HV. According to Fe-Sn binary phase diagram, it was speculated that this zone is mainly $\mathrm{Fe}_{3} \mathrm{Sn}$. In addition, hardness of magnesium side continues to decline, and the EDS results show that $\mathrm{Mg}_{2} \mathrm{Sn}$ exists in 5, 6 and 7 zone. The hardness of ferrite of dual phase steel is usually in the range of $120 \mathrm{HV}-150 \mathrm{HV}$, while martensitic is located on the range of $600 \mathrm{HV}-800 \mathrm{HV}$. Based on the empirical studies [16], hardness of $\mathrm{Mg}_{2} \mathrm{Sn}$ brittle phase is about $4.46 \mathrm{GPa}$ (446 HV), hardness of FeSn and $\mathrm{Fe}_{3} \mathrm{Sn}$ toughness phase are $2.30 \mathrm{GPa}(230 \mathrm{HV})$ and $0.17 \mathrm{GPa}(17 \mathrm{HV})$, respectively. Thus, hardness of these new phases is lower than that of martensite. Based on the above analysis, lower hardness of dual phase steel side is caused by the toughness of $\mathrm{FeSn}$ and $\mathrm{Fe}_{3} \mathrm{Sn}$, while magnesium side is caused by $\mathrm{Mg}_{2} \mathrm{Sn}$ with lower hardness than that of martensite.

Tensile-shear strength of Sn-foil added joints were finished by selecting from three groups of samples under the same welding parameters, and average value was considered as joint properties. It was found that when welding power is $1400 \mathrm{~W}$, welding speed is $30 \mathrm{~mm} / \mathrm{s}$, defocusing amount is $2 \mathrm{~mm}$, gas protection flow is $15 \mathrm{~L} / \mathrm{min}$, the average line load of steel/magnesium joints is $7.8 \mathrm{~N} / \mathrm{mm}$.

Figure 14 shows shear fracture position of $\mathrm{Sn}$-foil added sample. It was found that when welding power is $1300 \mathrm{~W}$, welding speed is $30 \mathrm{~mm} / \mathrm{s}$, shear sample is stripped along steel/magnesium transition zone (Fig. 14a). When welding power is $1400 \mathrm{~W}$, welding speed is $30 \mathrm{~mm} / \mathrm{s}$, shear sample is fractured along the upper DP600 dual phase steel weld (Fig. 14b). With the increase of thermal input, weld penetration and weld width increase. Comparison with failure samples under different laser powers, it was found that under the optimized parameters, sample is broken at steel side weld, while it is not damaged in steel/magnesium transition zone, which means that mechanical properties of steel/magnesium transition zone are better than that of weld. When the power is small, penetration depth is relatively shallow, which means that failure position is transition zone of steel/magnesium joint. From macroscopic point of view, cross-sectional shrinkage of specimen is small, which is characterized by brittle fracture.

In our previous work [10], Fracture micro-morphology with different failure positions was conducted, as shown in Fig. 15. It was discovered that magnesium side fracture is smooth, and cleavage step surface is small, which means cleavage fracture (Fig. 15a). Particles with dispersion distribution and a few micro-cracks were also detected in dual phase steel side (Fig. 15b). Further analysis was made, and steel side different zones were observed with different magnification, as shown in Fig. 16. It can be seen that there are local river patterns and some micro-cracks in weld (Fig. 16a), which displays the characteristics of cleavage fracture. The shallow gray matrix was embedded in some dark gray particles (Fig. 16b). There are many dimples on the fracture, which means ductile fracture. Based on the above analysis, it is deduced that fracture mode should be a mixed fracture with brittle inclusion.

The EDS results of joints were listed in Table 4. Here, it need be pointed out that $A$ and $B$ are fracture zone of magnesium side and steel side, respectively. In general, $\mathrm{Mg}$ is easy to oxidation, $\mathrm{O}$ element is detected in $\mathrm{A}$ and $B$ zones, and the $O$ content of magnesium side is significantly higher than that of steel side. In zone A, Mg, Sn, O are the main elements, while Fe element is less. It can be speculated that this zone is mainly $\mathrm{Mg}$ and $\mathrm{Mg}-\mathrm{Sn}$ solid solution. In zone $B$, it was found that the $\mathrm{Mg} / \mathrm{Sn}$ ratio is approximately 2:1, revealing that $\mathrm{Mg}_{2} \mathrm{Sn}$ is formed along the steel/magnesium fracture location. In addition, the $\mathrm{Mg} / \mathrm{Sn}$ ratio in C zone in steel side is close to 2:1, indicating that deep grey rule is $\mathrm{Mg}_{2} \mathrm{Sn}$ on weld fracture. In $\mathrm{D}$ region, there were a large number of $\mathrm{Sn}$ and $\mathrm{O}$ elements, as well as a small number of Fe and $\mathrm{Mg}$ elements, which means that matrix is mainly Sn. According to the above analysis, mechanical property for steel/magnesium joint is closely connected with the brittleness of $\mathrm{Mg}_{2} \mathrm{Sn}$ phase, how to regulate its brittleness is the key in order to improve the joint properties. 
Fig. 13 Energy spectrum of the longitudinal zones of weld. a detection location, $\mathbf{b}$ micro area $1, \mathbf{c} 2, \mathbf{d} 3, \mathbf{e} 4, \mathbf{f} 5, \mathbf{g} 6, \mathbf{h} 7$ energy spectrum
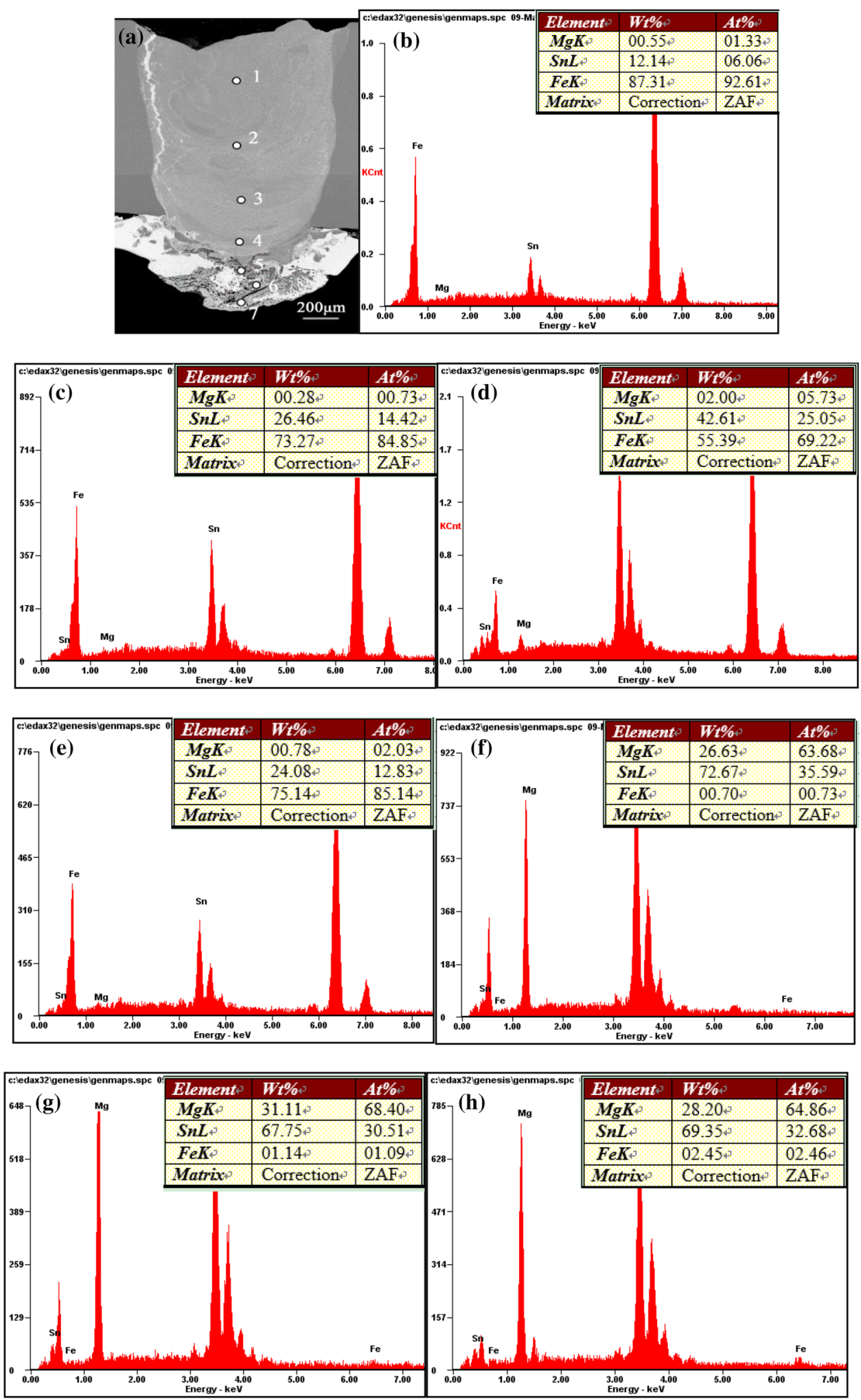
Table 3 Hardness of zones and corresponding chemical composition

\begin{tabular}{lcrrrl}
\hline Position & Hardness $\left(\mathrm{HV}_{0.5}\right)$ & \multicolumn{3}{l}{$\begin{array}{l}\text { Chemical composition } \\
\text { (at.\%) }\end{array}$} & Phase \\
\cline { 3 - 5 } & & $\mathrm{Mg}$ & \multicolumn{1}{c}{$\mathrm{Sn}$} & $\mathrm{Fe}$ & \\
\hline 1 & 398.5 & 1.33 & 6.06 & 92.61 & Rich-Fe \\
2 & 382.5 & 0.73 & 14.42 & 84.85 & Rich-Fe \\
3 & 158.4 & 5.73 & 25.05 & 69.22 & $\mathrm{Fe}_{3} \mathrm{Sn}$ \\
4 & 88.82 & 2.03 & 12.83 & 85.14 & Unknown \\
5 & 64.88 & 63.69 & 35.59 & 0.73 & $\mathrm{Mg}_{2} \mathrm{Sn}$ \\
6 & 64.72 & 68.40 & 30.51 & 1.09 & $\mathrm{Mg}_{2} \mathrm{Sn}$ \\
7 & 74.93 & 64.86 & 32.68 & 2.46 & $\mathrm{Mg}_{2} \mathrm{Sn}$ \\
\hline
\end{tabular}

\section{Conclusion}

The following conclusions can be made concerning the effects of adding Sn-foil on the microstructure and mechanical properties of laser welding joint for DP600 dual phase steel and AZ31 magnesium alloy:

1. When Sn-foil is added as interlayer, some defects, such as surface pit, spatter and softening in heat affected zone (HAZ), can be avoided, oxide and porosity are also no obvious in the weld. A good weld surface with continuous and uniform fish scale welding line is obtained by adding $\mathrm{Sn}$-foil.

2. Adding $\mathrm{Sn}$-foil laser welding is an effective way in joining steel to magnesium alloy. However, $\mathrm{Mg}_{2} \mathrm{Sn}$ is found along the fracture location of steel/magnesium transition zone, thus mechanical property of steel/ magnesium joint is affected by the brittleness of $\mathrm{Mg}_{2} \mathrm{Sn}$.
Fig. 14 Shear fracture location of welded specimens with Snfoil a $P=1300 \mathrm{~W}, \mathrm{~V}=30 \mathrm{~mm} / \mathrm{s}$, b $\mathrm{P}=1400 \mathrm{~W}, \mathrm{~V}=30 \mathrm{~mm} / \mathrm{s}$

Fig. 15 Microstructure of fracture surface a along steel/ magnesium transition zone, $\mathbf{b}$ magnesium side fracture
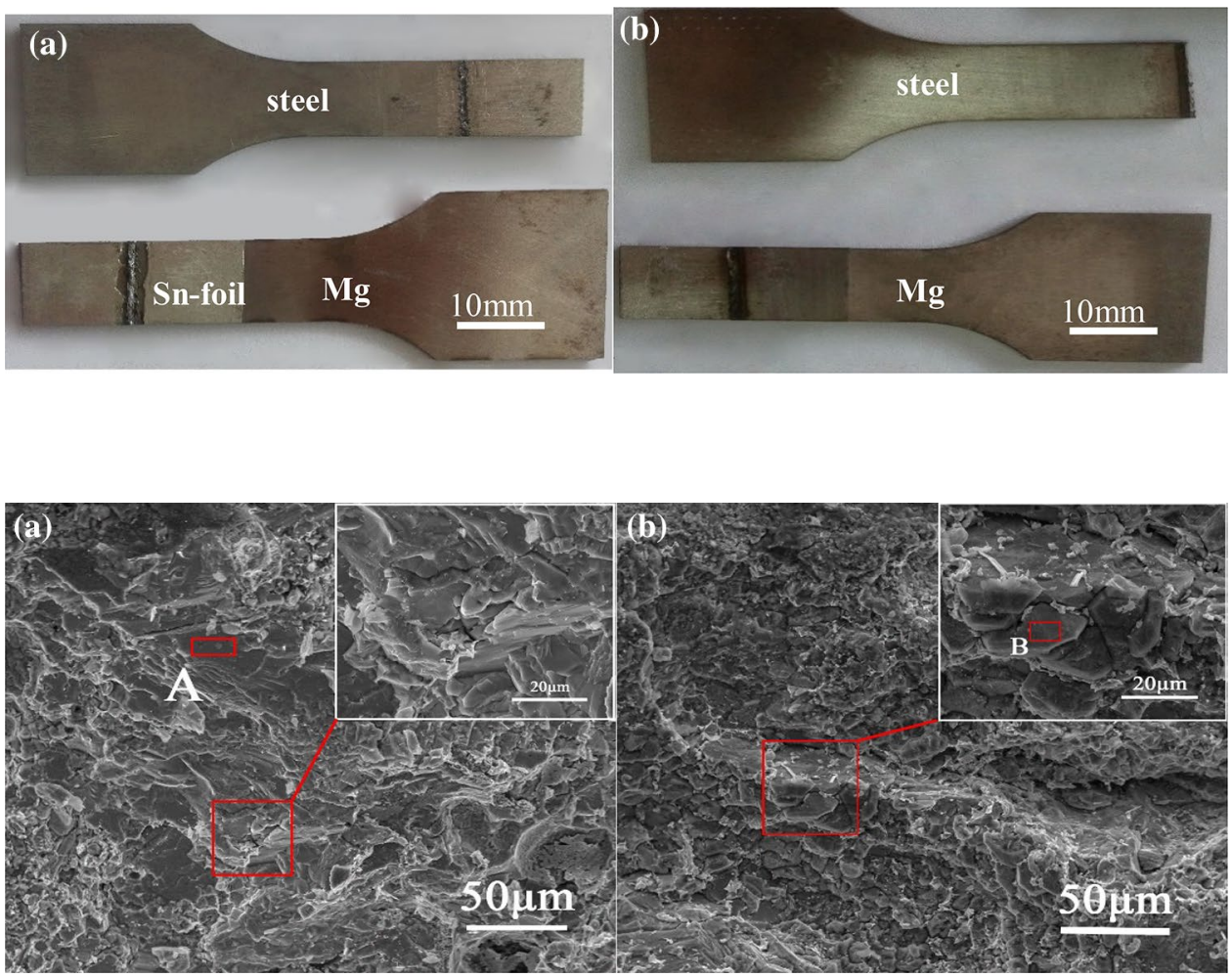
Fig. 16 Microscopic morphology of fracture surface after fracture along steel side weld fracture morphology a 1000 times, b 2000 times fracture morphology, c 4000 times fracture morphology
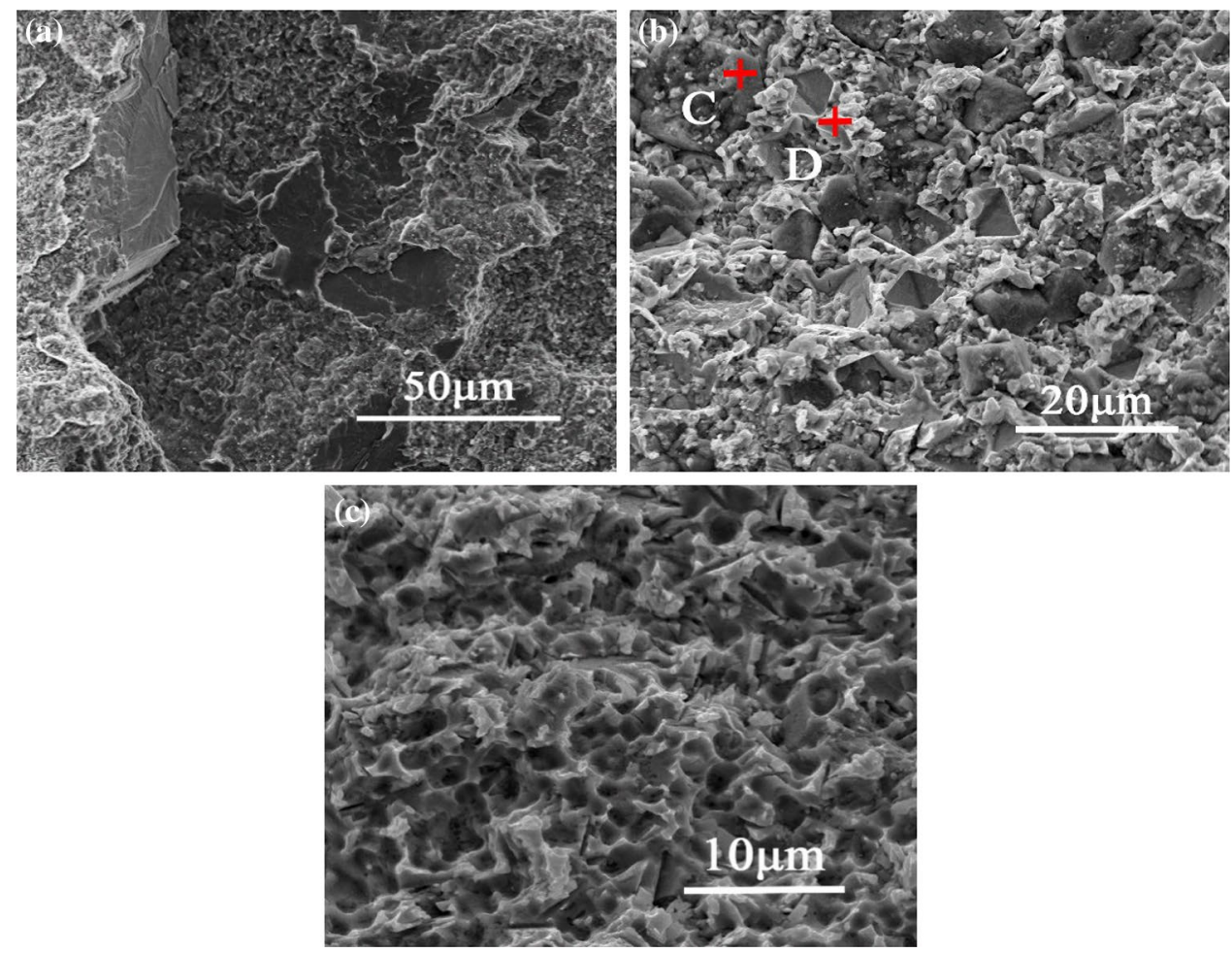

Table 4 EDS results of different fracture areas of joints

\begin{tabular}{llllllll}
\hline Region & \multicolumn{6}{l}{ Chemical composition (at.\%) } & \multicolumn{2}{l}{ Phase } \\
\cline { 2 - 7 } & O & Mg & Sn & Al & Fe & C & \\
\hline A & 40.49 & 23.76 & 20.61 & 0.94 & 3.14 & 11.07 & Unknown \\
B & 30.43 & 48.44 & 20.14 & - & 0.98 & - & Mg $_{2}$ Sn \\
C & 51.46 & 34.19 & 13.26 & - & 1.09 & - & Mg $_{2}$ Sn \\
D & 33.09 & 4.97 & 58.77 & - & 3.18 & - & Rich-Sn \\
\hline
\end{tabular}

Acknowledgements The authors would like to appreciate National Natural Science Foundation of China (Grant Nos. 51774125 and 51674112 ) and National Key Research and Development Project of China (Grant No. 2018YFB1107905).

\section{Compliance with ethical standards}

Conflict of interest The authors declare that they have no competing interests.

\section{References}

1. Decker RF (1998) Renaissance in magnesium. Adv Mater Process 9:31-35

2. Tan CW, Gong XT, Li LQ (2015) Laser welding-brazing characteristics of dissimilar metals $\mathrm{Mg} / \mathrm{Ti}$ with $\mathrm{Al}$ interlayers. Chin J Lasers 1:114-121

3. Fan ZJ, Gui LJ, Su RY (2014) Research and development of automotive lightweight technology. J Automot Saf Energy 1:1-16

4. Wahba M, Katayama S (2012) Laser welding of AZ31B magnesium alloy to $\mathrm{Zn}$-coated steel. Mater Des 35:701-706
5. Liu LM (2009) The interface behavior and weld ability study between magnesium alloys to heterogeneous materials. Weld Join 7:42-48

6. Liu LM, Qi X, Wu Z (2010) Microstructural characteristics of lap joint between magnesium alloy and mild steel with and without the addition of Sn element. Mater Lett 64:89-92

7. Liu LM, Qi X (2009) Effects of copper addition on microstructure and strength of the hybrid laser-TIG welded joints between magnesium alloy and mild steel. J Mater Sci 44:5725-5731

8. Zhao X, Song G, Liu LM (2006) Microstructure of dissimilar metal joint with magnesium alloys and steel. Trans China Weld Inst 27:53-56

9. Niu RF, Lin BH, Wang YN (2010) Evaporation loss of Mg element in pulsed laser welding of 5A05 aluminum alloy and distribution of micro-hardness of welding joint. Trans China Weld Inst 31:81-84

10. Zhou DW, Li T, Xu SH, Liu JS (2018) Numerical and experimental investigations in laser welding for steel and magnesium alloy. Lasers Manuf Mater Process 5(3):222-236

11. Zhang Y, Tan LP, Zhang CL (2013) Research on gap margin in laser butt welding of high-strength automobile steel with hot wire filler. Chin J Lasers 7:100-106 
12. Ding WB, Tong YG, Deng D (2014) Microstructure and mechanical prosperity of laser welded AZ91D Wrought magnesium alloy. Chin J Lasers 2:228-233

13. Shan JG, Zhang J, Zheng SQ (2009) Experimental study on pores in laser welding of magnesium alloys. Metal Mater Eng S3:234-239

14. Yamamoto HM (1966) Effect measurement of intermetallic compounds in iron-tin system: $\mathrm{Fe}_{5} \mathrm{Sn}_{3}$ and FeSn. J Phys Soc Jpn 21:1058-1062
15. Zhou DW, Liu JS, Xu SH, Peng P (2012) Thermal stability and elastic properties of $\mathrm{Mg}_{2} \mathrm{X}(\mathrm{X}=\mathrm{Si}, \mathrm{Ge}, \mathrm{Sn}, \mathrm{Pb})$ phases from firstprinciple calculations. Comput Mater Sci 51:409-414

16. Zhou DW, Liu JS, Lu YZ, Xu SH (2017) Effect of adding powder on joint properties of laser penetration welding for duel phase steel and aluminum alloy. Opt Laser Technol 94:171-179

Publisher's Note Springer Nature remains neutral with regard to jurisdictional claims in published maps and institutional affiliations. 